\title{
EHR Implementation and Financial Performance: The Case of Under-Resourced (High Medicaid) Nursing Homes
}

Neeraj Dayama ( $\sim$ neeraj.dayama@ttuhsc.edu )

Texas Tech University Health Sciences Center

Rohit Pradhan

West Liberty University

Ganisher Davlyatov

University of Oklahoma Health Sciences Center

Robert Weech-Maldonado

University of Alabama at Birmingham

\section{Research Article}

Keywords: nursing homes, skilled nursing facilities, Electronic Health Records (EHR), Health Information Technology (HIT), Medicaid, financial performance, total margin, health disparities

Posted Date: February 2nd, 2022

DOI: https://doi.org/10.21203/rs.3.rs-1281662/v1

License: (9) This work is licensed under a Creative Commons Attribution 4.0 International License. Read Full License 


\section{Abstract}

Background: The nursing home industry operates in a two-tiered system-high Medicaid nursing homes (Medicaid census $>85 \%$ ) cater disproportionately to marginalized populations, and exhibit both poorer quality of care and financial performance. Despite EHRs' purported positive impact on nursing home performance, high Medicaid nursing homes may be precluded from implementing EHR due to their precarious financial position. Compelling evidence on a return on investment (ROI) from HIT adoption may be required for reluctant nursing homes to invest in HIT systems. Utilizing the Resource-Based View (RBV), the primary purpose of this study was to understand whether EHR implementation in high Medicaid nursing homes is associated with improved financial performance.

Methods: EHR implementation data in high Medicaid nursing homes was collected via mail surveys sent to the Directors of Nursing (DON). We surveyed 1050 high Medicaid nursing homes and received 391 responses. The survey data was merged with the following secondary data sources: Brown University's LTCFocus, Area Health Resource File (AHRF), and the CMS Medicare Cost Reports. Multivariable regression model was used to understand the effect of EHR implementation on financial performance (total margin), adjusting for both organizational and market-level variables and potential non-response bias using propensity score inverse probability weighting.

Results: Approximately $76 \%$ of nursing homes in our study sample had either fully or partially implemented EHR. In our multivariable regression model, for every unit increase in total(average) EHR implementation, there was a $3.12 \%$ increase in the total margin $(p<0.05)$.

Conclusions: High Medicaid nursing homes with higher EHR implementation experienced superior financial performance. Improved financial performance may result from increased revenues and/or reduced costs via the ability to attract more remunerative residents, greater charge capture, improved practice efficiency, documentation management, medication safety, and adverse event reporting.

Implications for Policy or Practice: From a policy standpoint, our findings suggesting a sustainable economic argument for EHR implementation offer a strong rationale for targeted policy efforts, including extending subsidies, to ensure that US nursing homes are no longer the laggards in EHR implementation. For nursing home administrators, our findings suggest a potential business case-there may be long-term financial returns for the initial financial burden of EHR implementation.

\section{Introduction}

Nursing homes occupy an important position in the US healthcare system, providing services to a population that often has limited physical and cognitive abilities. The nursing home industry operates in a highly competitive and resource-constrained environment and faces several challenges, including financial viability and regulatory demands [1]. 
Mor and colleagues (2010) have argued that nursing homes operate in a two-tiered system with high Medicaid facilities (Medicaid census $>85 \%$ ) reporting lower quality of care as indicated by higher levels of health-related deficiencies and understaffing. These facilities typically report poorer financial performance, and therefore, face the perfect storm: poor quality of care coupled with limited resource availability. Unaddressed financial difficulties can not only lead to a further decline in quality but ultimately may lead to insolvency and closures, affecting the availability of institutional long-term care in rural and other underserved areas[2].

There is a broad academic and policy consensus that nursing homes would benefit from the implementation of Electronic Health Records (EHR). EHR can facilitate access and sharing of resident information improving resident safety and care coordination, reducing medical errors through applications such as alerts, reminders and clinical decision assists, and improving practice efficiency [36]. Nursing home researchers have reported that EHR can effective at reducing medication errors and urinary tract infections, improving adverse incidence reporting, and increasing immunization rates and resident satisfaction [7-9].

Prior literature has associated higher quality in nursing homes with improved financial performance; facilities that performed better on quality as measured by Donabedian's structure-process-outcome (SPO) model had a higher operating margin [10]. Therefore, EHR implementation in high Medicaid nursing homes has the potential to concomitantly address the two challenges administrators face: quality and financial performance.

Despite its purported impact on performance, market vagaries and policy choices have ensured that nursing homes lag in EHR implementation [11]. Nursing homes were excluded from the financial incentives created by the Health Information Technology for Economic and Clinical Health (HITECH) Act[12]. Experts and regulatory agencies have explicitly acknowledged the need to increase EHR penetration in nursing homes $[13,14]$. Financial concerns are one of the main barriers impeding widespread EHR implementation in nursing homes $[15,16]$. Installing EHR systems may involve investing in hardware, data migration, training, Information Technology (IT) support, and recurring maintenance costs [17]. A high Medicaid nursing home operating in an environment of constrained financial resources may be reluctant to invest in expensive EHR systems for two reasons: low current Medicaid revenues and uncertainty about future revenues. Industry advocacy groups like the American Health Care Association (AHCA) have claimed that Medicaid reimbursement rates cover only 70 percent of the actual cost of providing care to a nursing home resident [18]. High Medicaid nursing homes have few remunerative reimbursement avenues available to offset the cost of care impacting profitability. State budget-led constraints on Medicaid spending leading to cuts in nursing home reimbursements would further affect the appetite for large capital investments with hazy returns on investments (ROI) [19].

Therefore, we face a conundrum: nursing homes that would potentially benefit the most from EHR implementation may be the ones most reluctant to invest both as a matter of financial ability and choice. How do we encourage EHR implementation in high Medicaid nursing homes? Short of direct policy 
interventions, a possible avenue available is to establish a business case by demonstrating its positive impact on financial performance.

Although several studies have assessed the impact of EHR on hospital financial performance,[20-22] the empirical evidence in nursing homes is extremely limited. Hitt and Tambe (2016) have reported that operating costs were 2.3 percent higher for nursing homes that implemented EHR [23]. However, this study was limited to one state and the data may be out of date.

Our study contributes to the literature in three specific ways. First, by utilizing primary data collection, we offer a recent, comprehensive, and national-level examination of the financial impact of EHR implementation on nursing homes. Second, by focusing on high Medicaid nursing homes that serve a higher proportion of racial/ethnic minorities and residents of lower socioeconomic status, our findings may have a positive impact on the health and well-being of some of the most vulnerable Americans. Finally, our conceptual model and the employment of a rigorous analytical design, including controlling for organizational and market factors that may influence nursing home financial performance, lend greater credibility and strength to our findings.

\section{Conceptual Framework}

We utilize the resource-based view (RBV) of the firm to examine the relationship between EHR implementation and financial performance. RBV posits that organizational resources can lead to a firm's sustained competitive advantage if they are valuable, rare, inimitable, and organization-wide supported (VRIO) [24, 25]. A firm's information technology (IT)-based resources may be generic in nature per se; however, they can still result in sustained competitive advantage via tangible organizational resources and intangible IT-related resources [26]. The EHR system (IT infrastructure) adapted to the discrete needs of that facility and EHR-trained staff (human IT resources) can be regarded as tangible organizational resources in nursing homes. Intangible IT-related resources include workflow efficiencies, improved communication and coordination, and quicker access to information. After the introductory phase, the integration of the EHR processes in the workflow and EHR-trained staff may elevate EHR from a widely available 'off-the-shelf' system to a valuable, inimitable, rare, and organization-wide supported resource serving as a source of sustained competitive advantage [27] translating into improved financial performance.

Superior financial performance may be derived from increased revenues and/or reduced costs. An increase in revenue can result from higher market power: the facility may be able to attract remunerative residents (Medicare/private pay), with EHR serving as a potential 'signaling device' indicating higher quality. The increased bed utilization would also lead to improved revenues. Revenues may also increase due to comprehensive capturing of charges and coding accuracy. Reduced costs can result from gains in workflow efficiency, reduced expenditures on paper and transcription costs, and an overall reduction in waste [28-31]. In summary, EHR implementation can result in increased revenues and lower costs, translating into improved financial performance (Figure 1). 
Therefore, we hypothesize that:

$\mathrm{H}_{1}$ : High Medicaid nursing homes with higher EHR implementation will experience better financial performance

\section{Methods}

\section{Data:}

The study was conducted by merging survey and secondary data sources for the year 2017-2018. EHR implementation data was collected via mail surveys sent to Directors of Nursing (DON) in high Medicaid nursing homes in the US. To ensure a higher response rate, we followed a modified approach to Dillman's Total Design Method: three rounds of surveys with post-card reminders and follow-up phone calls from November 2017 through March 2018 [32]. All mailings included a link to the online survey. An incentive payment of $\$ 25$ was provided to survey respondents.

We constructed the analytical sample as follows: $85 \%$ or higher Medicaid census, and consistent with the prior approaches, we excluded nursing homes with $10 \%$ or higher private pay and/or $8 \%$ or higher Medicare (Mor et al. 2004). Our final sample size was 1050; we received 391 survey completes for a response rate of $37 \%$. We believe that our survey response rate was analogous to studies of this kind.

The survey data was merged with the following secondary data sources: Brown University's Long-Term Care Focus (LTCFocus), Area Health Resource File (AHRF), and the Centers for Medicare and Medicaid Services' (CMS) Medicare cost reports. LTCFocus provided nursing home organizational, demographic, and market data. AHRF was utilized to obtain demographic and market data at the county level. Medicare cost reports provided data on nursing home financial performance. The primary and secondary data were merged using nursing home provider ID and year.

\section{Variables:}

\section{Dependent variable:}

Total (profit) margin is a measure of overall financial performance and is defined as net income divided by total revenue. Net income is calculated as the difference between total revenue and total expenses of the nursing home.

$$
\text { Total profit margin }=\frac{\text { total revenue }- \text { total expenses }}{\text { total revenue }}
$$

\section{Independent variables:}

Mail surveys on EHR implementation assessed five functionalities: 1. administrative 2. documentation 3. order entry 4. results viewing 5. clinical tools. Administrative functions included processes and reporting 
such as scheduling systems and clinical task assignments. Documentation included health information and data such as resident demographics and medical history. Order entry had order management information including medication order entry. Results viewing had data on routing, managing, and presenting test results to clinical personnel for review. Clinical too/ had decision support system and telemonitoring/telehealth data. The items included in each functionality and their summary statistics are provided in Appendix A. Each item had four response options ( $0=$ not available, $1=$ paper only, $2=$ paper and electronic, $3=$ fully electronic). The composite EHR implementation score was the average of administrative (6 items), documentation ( 9 items), order entry ( 2 items), results viewing ( 4 items), and clinical tools (2 items) (Appendix A).

\section{Control variables:}

Control variables were identified based upon the factors that may affect the financial performance of a nursing home[1, 10] and include the following: organizational-level (size, occupancy rate, chain affiliation, ownership, payer mix, use of nurse practitioners/physician assistants, nurse staffing, acuity Index, and proportion of racial/ethnic minorities), and market/county-level factors (competition/HerfindahlHirschman Index (HHI), Medicare Advantage (MA) market penetration, per capita income, unemployment rate, location, poverty level, education level, and percent of population 65 and older).

In terms of organizational factors, size captured the total number of beds within the nursing home. Occupancy rate was the percentage of occupied nursing home beds. Chain affiliation reflected whether the nursing home was part of a chain $(0=$ freestanding; $1=$ chain affiliated). Ownership identified whether a nursing home was for-profit ( $0=$ for-profit), not-for-profit ( $1=$ not-for-profit) or government- owned ( $3=$ government-run). Payer mix was the proportion of the residents covered by Medicaid, Medicare, or private pay. Whether nurse practitioners/physician assistants were present at the nursing facility was coded as Yes $(=1)$ and No $(=0)$. Nurse staffing reflects four measures: Registered Nurse $(R N)$ staffing mix, RN hours per resident day (PRD), licensed practical nurse (LPN) hours PRD certified nursing assistant (CNA) hours PRD. The acuity index is an average measure of the resident's level of care needed. This measure was based on the number of residents needing assistance with various activities including mobility and activities of daily living (ADL). Proportion of racial/ethnic minorities was the proportion of nursing home residents who were Black, Hispanic, and other race/ethnicity.

In terms of market/county-level factors, market competition is measured as the sum of the squared of the market shares (based on beds) for nursing homes in a county. $\mathrm{HHI}$ is a continuous variable that ranges from 0 to 1 with lower values associated with higher competition - an HHI score close to zero would represent perfect competition. MA market penetration was calculated as the proportion of all Medicare beneficiaries in the county who were enrolled in a MA plan. Per capita income is a measure of the average income of individuals in a county. Unemployment rate was the percentage of individuals in the county who were unemployed. The location variable was coded as urban and rural where the urban was the reference category. Poverty level is percentage of persons in the county in poverty. Education level is the percentage of persons in the county aged 25 or above with a high school diploma or more. Percentage of 
population age 65 and older is calculated at the county level with total county population as the denominator.

\section{Data analysis:}

To adjust for potential non-response bias, we included propensity score weights in the regression analysis [33]. The propensity score weights were calculated as the inverse of the propensity scores for nursing homes that participated in the survey. To estimate the propensity score, we used a logistic regression model where we regressed respondence status (respondent $=1$, non-respondent $=0$ ) on the following variables: size, ownership status, chain affiliation, payer mix, acuity index, occupancy rate, race/ethnicity, RN staffing mix, RN hours per resident day, LPN hours per resident day, CNA hours per resident day, Medicare Advantage market penetration, per capita income, poverty, unemployment, education, competition $(\mathrm{HHI})$, location, and percent of individuals over 65 . Then we calculated the inverse of the propensity score, the propensity score weight to include in the models.

Multivariable linear regression was used to model the relationship between EHR implementation and financial performance, adjusting for both organizational and market level variables. Two models were run: first, the association of total (average) EHR functionalities with total margin; and second, the association of individual EHR functionalities with total margin. Stata 16 was utilized for data management and analysis, and statistical tests were evaluated at the 0.05 level of significance. The study was approved by the Institutional Review Board of the University of Alabama at Birmingham (IRB140828005) and informed consent was taken from all the survey participants.[34]

\section{Results}

Figure 2 shows the status of Electronic Health Record (EHR) implementation in our sample. Approximately $44 \%$ of nursing homes in the study sample had a fully implemented and operational EHR, $32 \%$ of nursing homes had a partially implemented and operational EHR, $11 \%$ of nursing homes were planning to implement EHR in the future, while $7 \%$ nursing homes currently did not have a plan to implement EHR. Therefore, approximately $76 \%$ of nursing homes in our study sample had implemented EHR-either fully or partially.

Figure 3 shows EHR implementation among nursing homes in our sample in terms of the five functionalities. While $46 \%$ nursing homes had fully implemented EHR for the more mundane administrative tasks, only $13 \%$ had implemented EHR for clinical tools (13\%).

Table 1 shows descriptive statistics for dependent, independent, and control variables. The mean total margin for our sample was $1.0 \%$. For our independent variables, the average of total EHR score was 0.96 . The means for individual functionalities were as follows: 1. EHR administration 1.36, 2. EHR documentation 1.11, 3. EHR order entry 1.18, 4. EHR results viewing 0.75 , and 5. EHR clinical tools 0.90. 
Table 1

Descriptive statistics of the sample $(\mathrm{N}=391)$

\begin{tabular}{|c|c|c|}
\hline Variables & Mean / frequency & Standard deviation / \% \\
\hline \multicolumn{3}{|l|}{ Dependent variable } \\
\hline Total margin & 1.67 & 0.71 \\
\hline \multicolumn{3}{|l|}{ Independent variable } \\
\hline \multicolumn{3}{|c|}{ Electronic health record implementation } \\
\hline Average & 1.06 & 0.04 \\
\hline Administrative function & 1.36 & 0.03 \\
\hline Documentation & 1.11 & 0.04 \\
\hline Order entry & 1.18 & 0.06 \\
\hline Results viewing & 0.75 & 0.04 \\
\hline Clinical tools & 0.90 & 0.05 \\
\hline \multicolumn{3}{|c|}{ Organization-level control variables } \\
\hline \multicolumn{3}{|l|}{ For-profit status } \\
\hline No & 137 & $35 \%$ \\
\hline Yes & 254 & $65 \%$ \\
\hline \multicolumn{3}{|l|}{ Chain affiliation } \\
\hline No & 165 & $42 \%$ \\
\hline Yes & 226 & $58 \%$ \\
\hline \multicolumn{3}{|c|}{ Employ nurse practitioners/physician assistants } \\
\hline No & 238 & $61 \%$ \\
\hline Yes & 153 & $39 \%$ \\
\hline Size (number of total beds) & 110.28 & 4.51 \\
\hline Occupancy rate & 84.61 & 0.93 \\
\hline Acuity index & 11.83 & 0.12 \\
\hline \multicolumn{3}{|l|}{ Payer mix } \\
\hline Private pay share & 7.06 & 0.38 \\
\hline Medicaid share & 87.10 & 0.43 \\
\hline Medicare share & 5.85 & 0.29 \\
\hline
\end{tabular}




\begin{tabular}{|lll|}
\hline Variables & Mean / frequency & Standard deviation / \% \\
\hline RN to total nurse ratio & 0.31 & 0.02 \\
\hline RN hours per resident day & 0.36 & 0.02 \\
\hline LPN hours per resident day & 0.80 & 0.02 \\
\hline CNA hours per resident day & 2.23 & 0.04 \\
\hline Percent of White residents & 60.95 & 2.22 \\
\hline Percent of Black residents & 20.86 & 1.97 \\
\hline Percent of Hispanic residents & 5.88 & 1.13 \\
\hline Percent of other race/ ethnicity residents & 12.33 & 1.31 \\
\hline Market-level control variables & & 0.02 \\
\hline Competition (Herfindahl- Hirschman Index) & 0.23 & 1.07 \\
\hline Medicare Advantage penetration & 30.33 & 989.96 \\
\hline Per capita income & 43400.00 & 0.14 \\
\hline Unemployment rate & 5.82 & 0.46 \\
\hline Location & & $9.4 \%$ \\
\hline Urban & 369 & 6.82 \\
\hline Rural & 22 & \\
\hline Poverty level & 18.00 & 0.00 \\
\hline Education level (high school diploma or more) & 84.81 & \\
\hline Percent of population 65 and older & 15.00 & \\
\hline
\end{tabular}

For organizational level control variables, the average bed size was 110 , the occupancy rate was $84.6 \%$, $42 \%$ of nursing homes were chain-affiliated, and $65 \%$ of nursing homes in our study sample were for profit. The average proportions of Medicaid, Medicare and private insurance residents were $87.1 \%, 5.9 \%$, and $7.1 \%$, respectively. The mean for Registered Nurse (RN)/nurse ratio was 0.3 , RN hours PRD was 0.4 , Licensed Practical Nurse (LPN) hours PRD was 0.8, and Certified Nursing Assistant (CNA) hours PRD was 2.2. With respect to the proportion race/ethnicity, $60.95 \%$ were White, $20.86 \%$ residents were Black, $5.88 \%$ residents were Hispanic, and $12.33 \%$ residents were classified as 'Other.'

For market-level control variables, the means were as follows: $\mathrm{HHI}$ index: 0.2, Medicare Advantage market penetration: $30.3 \%$, per capita income: $\$ 43,400$, unemployment rate: $5.8 \%$, urban location: $94 \%$. poverty level: $18 \%$, education level: $84.8 \%$, and percent population 65 and older: $15 \%$. 
Table 2 presents the results of the regression analysis for EHR functionalities on total margin. For Model 1 , with total (average) EHR functionalities as the independent variable, every unit increase in total (average) EHR implementation was associated with a $3.1 \%$ increase in total margin $(p<0.05)$. In Model 2 , there was no significant relationship between individual EHR functionality implementation and total margin (results not shown). With respect to the control variables, total margin was $0.13 \%$ points higher for a unit increase in occupancy rate $(p<0.001)$. 
Table 2

Regression of the relationship between nursing home EHR implementation and total margin $(\mathrm{N}=391)$

\begin{tabular}{|c|c|c|c|}
\hline \multirow{2}{*}{$\begin{array}{l}\text { Variables } \\
\text { EHR (average) }\end{array}$} & \multirow{2}{*}{$\begin{array}{l}\text { B-coefficient } \\
3.12^{\star}\end{array}$} & \multicolumn{2}{|c|}{ 95\% Confidence Intervals } \\
\hline & & 0.39 & 5.85 \\
\hline \multicolumn{4}{|c|}{ Organization-level control variables } \\
\hline \multicolumn{4}{|l|}{ For-profit status } \\
\hline No & \multicolumn{3}{|l|}{ reference } \\
\hline Yes & -2.32 & -6.19 & 1.55 \\
\hline \multicolumn{4}{|l|}{ Chain affiliation } \\
\hline No & \multicolumn{3}{|l|}{ reference } \\
\hline Yes & -0.48 & -3.14 & 2.18 \\
\hline \multicolumn{4}{|c|}{ Employ nurse practitioners/physician assistants } \\
\hline No & \multicolumn{3}{|l|}{ reference } \\
\hline Yes & 0.35 & -2.19 & 2.89 \\
\hline Size (number of total beds) & 0.01 & -0.01 & 0.03 \\
\hline Occupancy rate & $0.15^{\star \star}$ & 0.05 & 0.24 \\
\hline Acuity index & 0.18 & -0.59 & 0.96 \\
\hline \multicolumn{4}{|l|}{ Payer mix } \\
\hline Private pay share & \multicolumn{3}{|l|}{ reference } \\
\hline Medicaid share & -0.14 & -0.41 & 0.13 \\
\hline Medicare share & 0.14 & -0.31 & 0.58 \\
\hline RN to total nurse ratio & 4.01 & -23.20 & 31.23 \\
\hline RN hours per resident day & -5.57 & -23.39 & 12.25 \\
\hline LPN hours per resident day & -2.74 & -10.01 & 4.53 \\
\hline CNA hours per resident day & -1.44 & -3.74 & 0.85 \\
\hline Percent of White residents & \multicolumn{3}{|l|}{ reference } \\
\hline Percent of Black residents & -0.03 & -0.09 & 0.03 \\
\hline Percent of Hispanic residents & 0.00 & -0.08 & 0.09 \\
\hline
\end{tabular}




\begin{tabular}{|c|c|c|c|}
\hline \multirow{2}{*}{$\begin{array}{l}\text { Variables } \\
\text { Percent of other race/ethnicity residents }\end{array}$} & \multirow{2}{*}{$\begin{array}{l}\text { B-coefficient } \\
0.00\end{array}$} & \multicolumn{2}{|c|}{$95 \%$ Confidence Intervals } \\
\hline & & -0.08 & 0.08 \\
\hline \multicolumn{4}{|l|}{ Market-level control variables } \\
\hline Competition (Herfindahl- Hirschman Index) & 4.99 & -0.84 & 10.83 \\
\hline Medicare advantage penetration & -0.03 & -0.13 & 0.08 \\
\hline Per capita income & 0.00 & 0.00 & 0.00 \\
\hline Unemployment rate & -0.64 & -1.78 & 0.49 \\
\hline \multicolumn{4}{|l|}{ Location } \\
\hline Urban & \multicolumn{3}{|l|}{ reference } \\
\hline Rural & -4.77 & -11.46 & 1.91 \\
\hline Poverty level & 0.21 & -0.15 & 0.58 \\
\hline Education level (high school diploma or more) & -0.06 & -0.45 & 0.32 \\
\hline Percent of population 65 and older & -0.18 & -0.60 & 0.23 \\
\hline${ }^{\star} p<0.05, * \star p<0.01, * \star \star p<0.001$ & & & \\
\hline
\end{tabular}

\section{Discussion}

The primary purpose of this study was to understand whether EHR implementation in high Medicaid nursing homes is associated with improved financial performance. We focused on high Medicaid nursing homes because they are classified as the "lower tier" among the nursing homes: experience poor quality of care, are under-resourced, and disproportionately serve the poor and the minorities. [35]. Our study provides encouraging new evidence that these nursing homes "at-risk" for closure may be able to improve their fiscal situation through EHR implementation.

Previous surveys in nursing homes report sharply variable implementation rates ranging between 18$84 \%$ [36-38], whereas the implementation rates in hospitals and physician offices exceed $90 \%$ [39, 40]. A 2016 national survey reported that $67 \%$ of nursing homes had implemented EHR [11]. Our results suggest that only $44 \%$ of high Medicaid nursing homes had a fully implemented and operational EHR. Although our samples are different, we may cautiously speculate that high Medicaid nursing homes lag further behind average US nursing homes in EHR implementation. A financial incentive structure analogous to the (HITECH) Act may be required to stimulate EHR implementation in nursing homes particularly in the case of high Medicaid facilities.

As hypothesized, high Medicaid nursing homes with higher EHR implementation experienced superior financial performance. Increased revenues in nursing homes may result from greater charge capture and 
time savings from improved practice efficiency, as demonstrated in hospital research [21]. Nursing homes could potentially justify greater reimbursement adjustment rates by improving coding efficiency, fully utilizing reimbursement methods, and appropriately recording comorbid illnesses (Britton, 2015). Documentation management, medication safety, adverse event reporting, reduced time to access resident data, automated coding, and claims management are some of the elements that may enhance efficiency and lower costs in nursing homes. [9]. Savings in operating expenses also could stem from a reduction in redundant tests, costs related to paper records, chart pulls, and transcription [30, 31, 41]. Finally, we also speculate that nursing homes may be able to achieve a more remunerative patient profile by taking advantage of EHR implementation to signal superior quality enhancing their market power.

This study should provide cautious optimism to administrators of high Medicaid nursing homes wrestling with the decision to invest in an EHR system while navigating a financially precarious climate. Our findings suggesting a positive correlation between EHR implementation and profitability provides nursing home administrators with a persuasive incentive to prioritize EHR-related investments. It's important to note that our data shows a significant gap between EHR implementation for relatively simple administrative tasks and more sophisticated clinical tasks that necessitate a higher level of employee training. Therefore, it is critical to emphasize that to realize the full potential of EHR systems, healthcare organizations must continue investing in IT infrastructure and human resources.

Policymakers and regulators may not be concerned directly with nursing homes' financial performance but their future viability and the ability to deliver a minimally adequate level of care are certainly important considerations. Nursing homes were excluded from HITECH Act subsidies which has hampered EHR implementation within this sector [11]. However, policymakers may have a genuine concern: even if subsidies were extended to nursing homes, would facilities, especially those with high Medicaid census, have the financial wherewithal required to make the continued investments necessary to maximize their utility? We believe that our findings may be helpful here: A business case for EHR implementation suggests a possible scenario where subsidies motivate the initial implementation whereas the financial benefits ensure that the facilities treat them as an asset and not a mere regulatory burden and continue to make the requisite investments.

\section{Limitations}

A cross-sectional study contributes to the extant literature; however, it cannot evaluate longitudinal effects over time. Researchers and policymakers would benefit greatly from a federal mandate collecting longitudinal data on EHR implementation in nursing homes. Despite our best attempts to measure EHR implementation, there is a need to better operationalize the combined effect of individual EHR functionalities by weighting individual functionalities, as done in the case of hospitals [42]. Finally, we must acknowledge the possibility of survey response bias as nursing homes that have implemented or planning to implement EHR have a higher likelihood of responding to surveys of this nature.

\section{Conclusions}


This research improves our understanding of the financial impact of EHR implementation in high Medicaid nursing homes. These financially imperiled facilities are responsible for the health and wellbeing of some of the most vulnerable Americans. We believe that our findings suggesting a sustainable economic argument for EHR implementation offer a strong rationale for targeted policy efforts, including extending subsidies, to ensure that US nursing homes are no longer the laggards in EHR implementation. It may no longer be feasible to exclude nursing homes from incentives available to other sectors of the US healthcare system. For nursing home administrators, our findings suggest potential business case for EHR implementation where they benefit from prioritizing long-term financial returns for the initial financial burden of EHR implementation.

\section{List Of Abbreviations}

ADL $\quad$ Activities of Daily Living

AHCA American Health Care Association

AHRF Area Health Resource Files

CMS Centers for Medicare And Medicaid Services

CNA Certified Nursing Assistant

DON Director of Nursing

$\mathrm{HHI} \quad$ Herfindahl-Hirschman Index

HIT Health Information Technology

HITECH Health Information Technology for Economic and Clinical Health

IRB Institutional Review Board

RN Registered Nurse

LPN Licensed Practical Nurse

MA Medicare Advantage

PRD Per Resident Day

RBV Resource Based View

ROI Return on Investment

SPO Structure-Process-Outcomes 


\section{Declarations}

\section{Ethics approval and consent to participate}

This study was performed in accordance with the Declaration of Helsinki ethical principles for medical research involving human subjects. It was reviewed and approved by the University of Alabama at Birmingham's Institutional Review Board (IRB-140828005). Informed consent to participate was obtained from all survey participants.

\section{Consent for publication}

Not applicable.

\section{Availability of data and materials}

The datasets used and/or analyzed during the current study are available from the corresponding author on reasonable request.

\section{Competing interests}

The authors declare no competing interests.

\section{Funding}

This research was supported by the Agency for Healthcare Research and Quality (1R01HS023345-01).

\section{Authors' contributions}

Neeraj Dayama contributed to the development and writing of the manuscript. Ganisher Davlyatov collected and analyzed data, prepared the tables, and contributed to the writing. Rohit Pradhan and Robert Weech-Maldonado conceptualized and contributed to the development of the manuscript. All authors reviewed the manuscript.

\section{References}

1. Weech-Maldonado R, Lord J, Pradhan R, Davlyatov G, Dayama N, Gupta S, Hearld L. high medicaid nursing homes: organizational and market factors associated with financial performance. Inquiry: J Health Car. 2019; 56. doi: https://doi.org/10.1177/0046958018825061.

2. Bowblis JR. Ownership conversion and closure in the nursing home industry. Health Econ. 2011; 20(6):631-644. doi: https://doi.org/10.1002/hec.1618.

3. Radley DC, Wasserman MR, Olsho LEW, Shoemaker SJ, Spranca MD, Bradshaw B. Reduction in medication errors in hospitals due to adoption of computerized provider order entry systems. J Am 
Med Inf Assoc. 2013;20(3):470-476.

4. Tanner C, Gans D, White J, Nath R, Pohl J. Electronic health records and patient safety. Appl Clin Inform. 2015;6(01):136-147.

5. Castaneda C, Nalley K, Mannion C, Bhattacharyya P, Blake P, Pecora A, Goy A, Suh KS. Clinical decision support systems for improving diagnostic accuracy and achieving precision medicine. $J$ Clin Bioinform. 2015;5(1): 4.

6. Adler-Milstein J, Jha AK. HITECH Act drove large gains in hospital electronic health record adoption. Health Aff. 2017;36(8):1416-1422.

7. Pierson S, Hansen R, Greene S, Williams C, Akers R, Jonsson M, Carey T. Preventing medication errors in long-term care: results and evaluation of a large scale web-based error reporting system. Qual saf health care. 2007;16(4):297-302. doi: 10.1136/qshc.2007.022483.

8. Bjarnadottir RI, Herzig CTA, Travers JL, Castle NG, Stone PW. Implementation of electronic health records in us nursing homes. Comput Inform Nurs. 2017;35(8): 417-424. doi:

$10.1097 /$ CIN.0000000000000344 [doi].

9. Kruse CS, Mileski M, Vijaykumar AG, Viswanathan SV, Suskandla U, Chidambaram Y. Impact of electronic health records on long-term care facilities: Systematic review. JMIR Med Inform. 2017;5(3): e35.

10. Weech-Maldonado R, Pradhan R, Dayama N, Lord J, Gupta S. Nursing home quality and financial performance: is there a business case for quality? Inquiry: J Health Car 2019;56. doi: https://doi.org/10.1177/0046958018825191.

11. Alvarado CS, Zook K, Henry J. Electronic health record adoption and interoperability among U.S. skilled nursing facilities in 2016 In., vol. ONC Data Brief No. 39: Office of National Coordinator for Health Information Technology (ONCHIT); 2017.

12. Vest JR, Jung H-Y, Wiley Jr K, Kooreman H, Pettit L, Unruh MA. Adoption of health information technology among US nursing facilities. J Am Med Dir Assoc. 2019;20(8):995-1000. e1004.

13. Dougherty ML, Williams M, Millenson ML, Harvell J. EHR payment incentives for providers ineligible for payment incentives and other funding study: Office of Disability, Aging and Long-Term Care Policy, Office of the Assistant Secretary for Planning and Evaluation, US Department of Health and Human Services; 2013.

14. Patient Protection and Affordable Care Act. 45 CFR Part 156. In: Vol 84, No 42. US Department of Health and Human Services; 2019: 7610.

15. Abramson EL, McGinnis S, Edwards A, Maniccia DM, Moore J, Kaushal R. Electronic health record adoption and health information exchange among hospitals in New York State. J Eval Clin Prac. 2012;18(6):1156-1162.

16. Filipova AA. Electronic health records use and barriers and benefits to use in skilled nursing facilities. CIN: Computers, Informatics, Nursing. 2013;31(7):305-318.

17. Fleming NS, Culler SD, McCorkle R, Becker ER, Ballard DJ. The financial and nonfinancial costs of implementing electronic health records in primary care practices. Health Aff. 2011;30(3):481-489. 
18. American Health Care Association. Financial struggle of nursing homes puts Medicaid reimbursement rates back in the spotlight 2020. [https://www.ahcancal.org/News-andCommunications/Press-Releases/Pages/Financial-Struggle-of-Nursing-Homes-Puts-MedicaidReimbursement-Rates-Back-in-the-Spotlight.aspx]. Accessed 20 Dec 2021.

19. Bowblis JR, Applebaum R. How does Medicaid reimbursement impact nursing home quality? The effects of small anticipatory changes. Health Serv Res. 2017; 52(5):1729-1748.

20. Wang T, Wang Y, McLeod A. Do health information technology investments impact hospital financial performance and productivity? Int J Account Inf Syst.2018;28:1-13.

21. Collum TH, Menachemi N, Sen B. Does electronic health record use improve hospital financial performance? Evidence from panel data. Health Care Manage Rev.2016;41(3):267-274. doi: 10.1097/HMR.0000000000000068 [doi].

22. Fleming NS, Becker ER, Culler SD, Cheng D, McCorkle R, Graca Bd, Ballard DJ. The impact of electronic health records on workflow and financial measures in primary care practices. Health Serv Res.2014;49(1pt2):405-420.

23. Hitt LM, Tambe P. Health care information technology, work organization, and nursing home performance. ILR Review. 2016;69(4):834-859.

24. Upadhyay S, Weech-Maldonado R, Lemak CH, Stephenson A, Mehta T, Smith DG. Resource-based view on safety culture's influence on hospital performance: The moderating role of electronic health record implementation. Health Care Manage Rev. 2020;45(3):207-216.

25. Barney J. Firm resources and sustained competitive advantage. J Manage. 1991;17(1):99-120. doi: $10.1177 / 014920639101700108$.

26. Bharadwaj AS. A resource-based perspective on information technology capability and firm performance: An empirical investigation. MIS Quart. 2000;24(1):169-196. doi: 10.2307/3250983

27. Miller RH, West C, Brown TM, Sim I, Ganchoff C. The value of electronic health records in solo or small group practices. Health Aff. 2005;24(5):1127-1137.

28. Menachemi N, Collum TH. Benefits and drawbacks of electronic health record systems. Risk Manag Healthc Policy. 2011;4:47-55. doi: 10.2147/RMHP.S12985 [doi].

29. Levine DM, Healey MJ, Wright A, Bates DW, Linder JA, Samal L. Changes in the quality of care during progress from stage 1 to stage 2 of Meaningful Use. J Am Med Inf Assoc. 2016;24(2):394-397.

30. Chen P, Tanasijevic MJ, Schoenenberger RA, Fiskio J, Kuperman GJ, Bates DW. A computer-based intervention for improving the appropriateness of antiepileptic drug level monitoring. Am J Clin Path. 2003;119(3):432-438.

31. Wang SJ, Middleton B, Prosser LA, Bardon CG, Spurr CD, Carchidi PJ, Kittler AF, Goldszer RC, Fairchild DG, Sussman AJ. A cost-benefit analysis of electronic medical records in primary care. Am J Med. 2003;114(5):397-403.

32. Dillman DA. Mail and telephone surveys: The total design method, vol. 19: Wiley New York; 1978. 
33. Austin PC. An introduction to propensity score methods for reducing the effects of confounding in observational studies. Multivariate Behav Res. 2011;46(3):399-424.

34. Goodyear MD, Krleza-Jeric K, Lemmens T. The declaration of Helsinki. In., vol. 335: BMJ. 2007;624625.

35. Mor V, Zinn J, Angelelli J, Teno JM, Miller SC. Driven to tiers: socioeconomic and racial disparities in the quality of nursing home care. Milbank Q. 2004;82(2):227-256.

36. Zhang N, Lu SF, Xu B, Wu B, Rodriguez-Monguio R, Gurwitz J. Health information technologies: Which nursing homes adopted them? J Am Med Dir Assoc. 2016;17(5):441-447.

37. Abramson EL, Edwards A, Silver M, Kaushai R, investigators $H$. Trending health information technology adoption among New York nursing homes. Am J Manag Care. 2014;20(11 Spec No. 17): eSP53-59. doi: 85901 [pii].

38. Wang T, Biedermann S. Adoption and utilization of electronic health record systems by long-term care facilities in Texas. Perspectives in health information management. 2012;9 1g.

39. Jamoom E, Yang N. Table of electronic health record adoption and use among office-based physicians in the U.S., by State: 2015 National Electronic Health Records Survey. 2016.

40. Charles D, Gabriel M, Furukawa MF. Adoption of electronic health record systems among US nonfederal acute care hospitals: 2008-2014. ONC Data Brief. 2013;9:1-9.

41. Bates DW, Kuperman GJ, Rittenberg E, Teich JM, Fiskio J, Ma'luf N, Onderdonk A, Wybenga D, Winkelman J, Brennan TA. A randomized trial of a computer-based intervention to reduce utilization of redundant laboratory tests. American J Med. 1999;106(2):144-150.

42. HIMSS Electronic Medical Records Adoption Model. 2018.

[https://www.himssanalytics.org/europe/electronic-medical-record-adoption-model]. Accessed 10 Oct 2021.

\section{Figures}

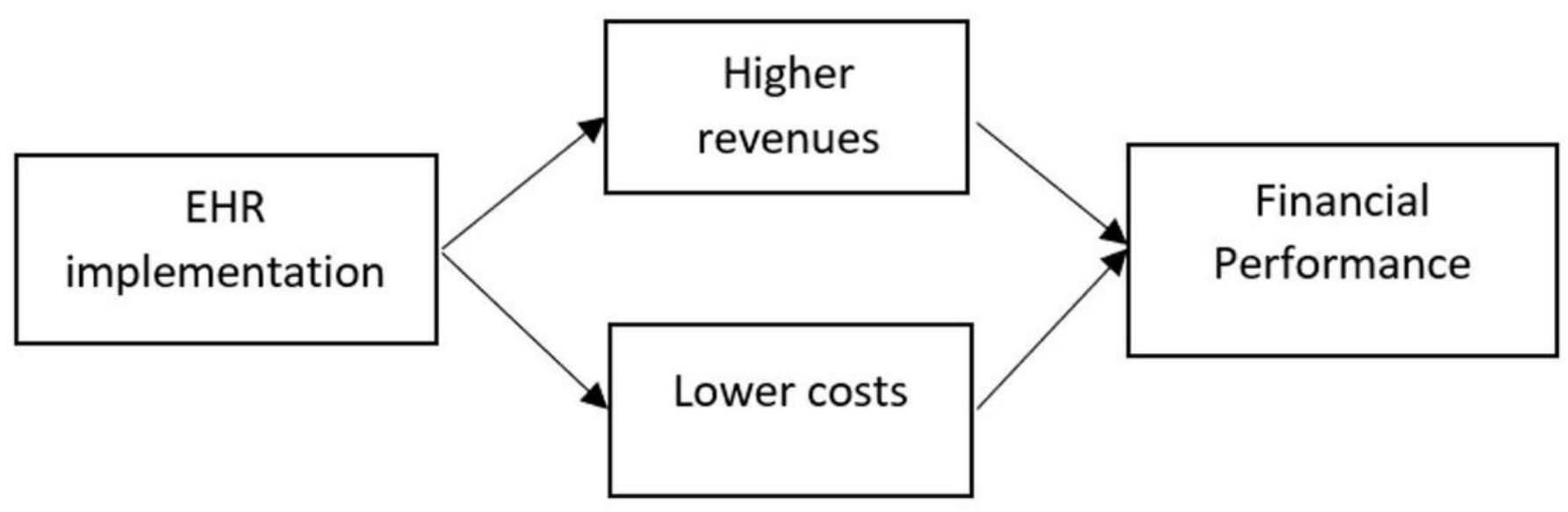




\section{Figure 1}

\section{Conceptual Framework}

Conceptual framework showing relationship between Electronic Health Records (EHR) adoption and nursing home financial performance

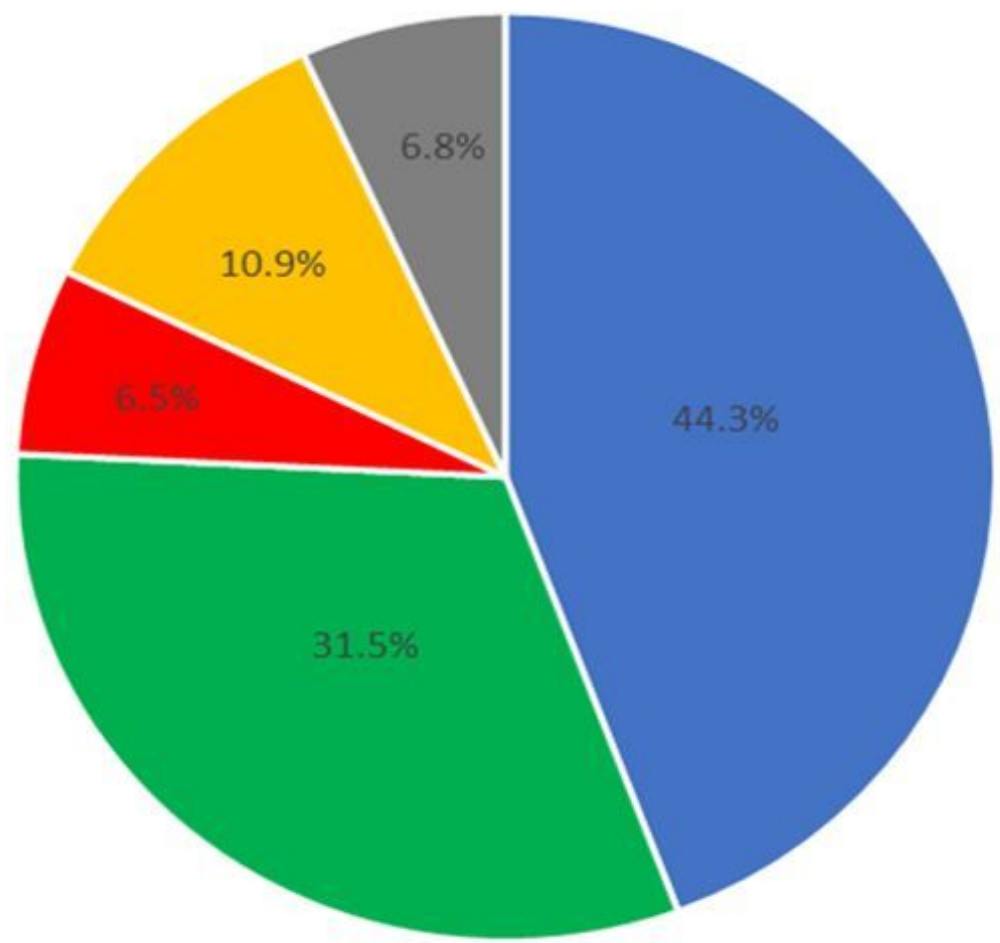

- Fully implemented and operational

- Partially implemented/operational

- Selected, with signed vendor contract, but not operation/in use yet

- Plan to select and implement in the future

- Do not have current plans to implement

\section{Figure 2}

\section{Status of EHR Implementation in high Medicaid nursing homes $(n=391)$}

Status of Electronic Health Record (EHR) implementation in high Medicaid nursing homes $(n=391)$. 44.3\% nursing homes (blue) had a fully implemented and operational EHR. 31.5\% (green) nursing homes had a partially implemented and operational EHR. 6.5\% (red) nursing homes had selected a vendor and signed vendor contract but did not have an EHR in operation. 10.9\% (yellow) of nursing homes were 
planning to implement EHR in the future. $6.8 \%$ (gray) nursing homes currently did not have a plan to implement EHR.

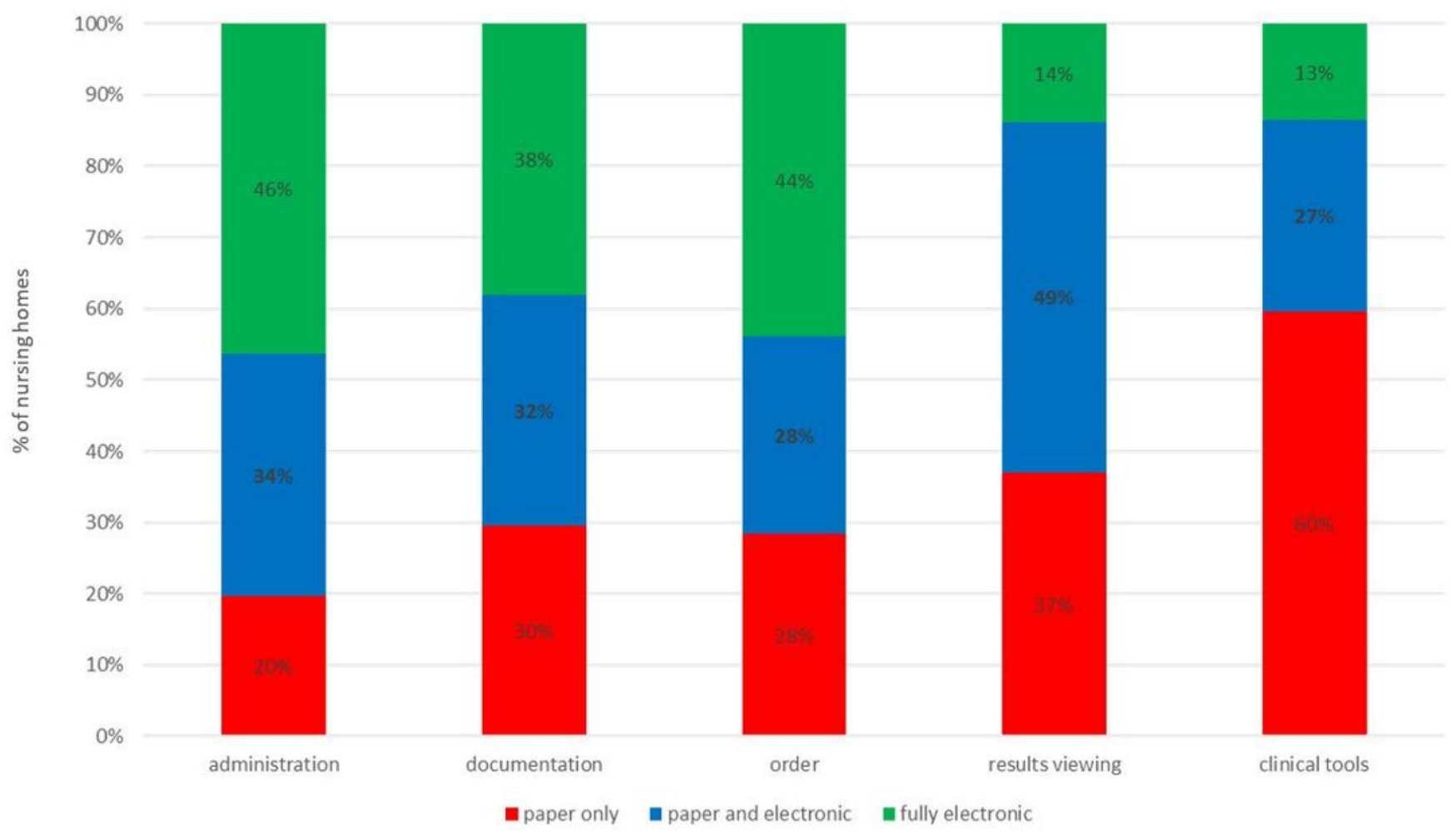

Figure 3

EHR implementation in high Medicaid nursing homes by functionality $(n=391)$

Implementation of EHR functionalities (administration, documentation, order, results viewing, and clinical tools) in high Medicaid nursing homes $(\mathrm{n}=391)$ by type of health record (red=paper only, blue=paper and electronic, and green=fully electronic).

\section{Supplementary Files}

This is a list of supplementary files associated with this preprint. Click to download.

- AppendixA.docx 